\title{
Effect of Chemical Treatment on Physical, Mechanical and Thermal Properties of Ladies Finger Natural Fiber
}

\author{
S. I. Hossain, ${ }^{1}$ M. Hasan, ${ }^{1,2}$ Md. N. Hasan, ${ }^{1}$ and A. Hassan ${ }^{2}$ \\ ${ }^{1}$ Department of Materials and Metallurgical Engineering, Bangladesh University of Engineering and Technology, \\ Dhaka 1000, Bangladesh \\ ${ }^{2}$ Department of Polymer Engineering, Faculty of Chemical Engineering, Universiti Teknologi Malaysia, 81310 Skudai, Johor, Malaysia
}

Correspondence should be addressed to M. Hasan; mahbubmmebuet@gmail.com

Received 2 May 2013; Accepted 4 September 2013

Academic Editor: Aiguo Xu

Copyright (C) 2013 S. I. Hossain et al. This is an open access article distributed under the Creative Commons Attribution License, which permits unrestricted use, distribution, and reproduction in any medium, provided the original work is properly cited.

In present research, natural fiber obtained from ladies finger plant was chemically treated separately using alkali $(2 \% \mathrm{NaOH})$, chromium sulfate $\left(4 \% \mathrm{Cr}_{2}\left(\mathrm{SO}_{4}\right)_{3} \bullet 12\left(\mathrm{H}_{2} \mathrm{O}\right)\right)$, and chromium sulfate and sodium bicarbonate $\left(4 \% \mathrm{Cr}_{2}\left(\mathrm{SO}_{4}\right)_{3} \bullet 12\left(\mathrm{H}_{2} \mathrm{O}\right)+\mathrm{NaHCO}_{3}\right)$. Both raw and chemically treated fibers were subsequently characterized using mechanical (tensile), structural (Fourier transform infrared spectroscopy and scanning electron microscopy), and thermal (thermogravimetric) analysis. Fourier analysis showed the presence of $(-\mathrm{OH})$ group in the ladies plant fiber. Scanning electron micrographs revealed rougher surface in case of alkali treated fiber, while thin coating layer was formed on the fiber surface during other two treatments. Tensile test on ladies finger single fiber was carried out by varying span length. The tensile strength and Young's modulus values were found to be increased after chemical treatment. For both raw and chemically treated fibers, Young's modulus increased and tensile strength decreased with increase in span length. Thermogravimetric analysis indicated the same level of thermal stability for both raw and treated ladies finger fibers.

\section{Introduction}

Natural fibers are gaining progressive account as renewable, environmentally acceptable, and biodegradable starting material for industrial applications, technical textiles, composites, pulp, and paper, as well as for civil engineering and building activities. Natural fibers reinforced composites combine acceptable mechanical properties with a low density [1]. In recent years, wide range of research has been carried out on fiber reinforced polymer composites [2-11].

Typical reinforcements for composites with plastic matrix are various synthetic fibers such as glass, graphite, boron, metallic, and ceramic materials. These materials are heavy, expensive, and harmful to environment. The replacement of inorganic fibers with comparable natural fibers provides weight and cost reduction. The advantages of using natural fibers also include high specific stiffness and mechanical strength, availability, reduced energy consumption, low hardness which minimizes the wear of processing equipment, renewability, recyclability, nonhazard, and biodegradability. Natural fiber reinforced composites are suitably applicable for aerospace, leisure, construction, sport, packaging, and automotive industries [12-14]. However, the main drawback of natural fiber reinforced polymer composites is the incompatibility between the hydrophilic natural fiber and hydrophobic matrices. This leads to undesirable properties of the composites. It is therefore necessary to modify the fiber surface by employing chemical modifications to improve the adhesion between the fiber and matrix [15-18]. The objective of present research is to characterize raw and chemically treated ladies finger natural fibers by finding out their physical, mechanical, and thermal properties. The properties of raw ladies finger fiber are also compared with those of chemically treated ones.

\section{Experimental Procedure}

2.1. Chemical Treatment of Fiber. Three types of chemical treatments were performed on the ladies finger fiber. Fiber was extracted from the stem of a ladies figure tree (Figure 1). For alkali treatment, the fiber was treated with $2 \% \mathrm{NaOH}$ solution at $70^{\circ} \mathrm{C}$ for about two and a half hours. A single stage treatment (SST), which is basic chromium sulfate solution treatment ( $\mathrm{pH} 4)$, was performed by a 3-hour shaking of fiber 


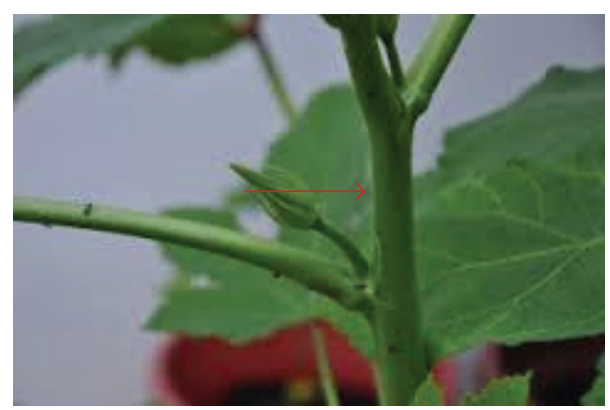

FIgURE 1: Picture of a ladies finger tree.

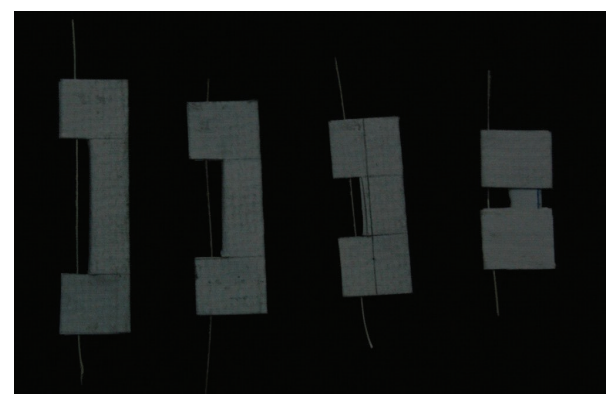

FIGURE 2: Specimens for tensile test.

in $4 \% \mathrm{Cr}_{2}\left(\mathrm{SO}_{4}\right)_{3} \cdot 12\left(\mathrm{H}_{2} \mathrm{O}\right)$ solution. The double stage treatment (DST) was performed by continuing the $4 \% \mathrm{Cr}_{2}\left(\mathrm{SO}_{4}\right)_{3}$ • $12\left(\mathrm{H}_{2} \mathrm{O}\right)$ treatment with the addition of $\mathrm{NaHCO}_{3}$ solution for another 2 hours.

2.2. Tensile Test. Tensile test of single ladies finger fiber was carried out by varying span length at 5, 15, 25, and $35 \mathrm{~mm}$ using a tensile testing machine. The fibers were glued in a paper frame (Figure 2) to ensure a good gripping and straight direction to the test clamps. Diameter of single fiber was measured by using a scanning electron microscope (SEM). The paper frame was carefully placed in between the jaws of the load cell. Load cell of $50 \mathrm{~N}$ was used, and crosshead speed was $4 \mathrm{~mm} / \mathrm{min}$.

2.3. FTIR Spectroscopy. The infrared spectra of fiber were recorded on a Nicolet 380 spectrophotometer with coaddition of 32 scans. Powdered sample was taken for FTIR spectroscopy. Then potassium bromide $(\mathrm{KBr})$, which acts as a reagent, was mixed $(\mathrm{KBr}$ : sample $=100: 1)$ with them in a mortar pestle. The mixture was then taken in a dice of specific dimensions. The pellet was formed by pressing with a hand press machine and was placed on the sample holder. The IR spectrum obtained is presented in the Results and Discussion section.

2.4. Scanning Electron Microscopy. Surface morphology of the raw and chemically treated fibers was observed under a scanning electron microscope (Philips XL 30). The fiber surface was initially made conductive by applying gold coating using a sputtering machine. The fiber was then taken inside
SEM, vacuum was created, and micrographs were taken. The diameter of the fiber was also measured using the same microscope.

2.5. Thermogravimetric Analysis. Thermogravimetric analysis was carried out for determining thermal stability of ladies finger fiber. TGA method used was based on continuous measurement of weight on a sensitive balance (called a thermobalance) as sample temperature was increased in an inert atmosphere. This is referred to as nonisothermal TGA. Data were recorded as a thermogram of weight versus temperature.

\section{Results and Discussion}

3.1. Tensile Properties. Tensile properties (Young's modulus and tensile strength) of both raw and chemically treated single fibers were obtained from stress/strain curves. In order to remove the grip effect during tensile test, the Young's modulus values were corrected using a method described in [19]. The variation of Young's modulus and tensile strength is shown in Figures 3 and 4, respectively. The tensile strength decreased, while Young's modulus increased with increase in span length $[20,21]$. As mentioned by Bledzki and Gassan [22], the longer the stressed distance of the natural fiber, the more inhomogeneities (flaws) in the stressed fiber segment that weaken the structure. Thus increasing fiber length inevitably reduces the strength of the fiber.

During alkali treatment, hemicellulose and lignin were removed. The interfibrillar region is likely to be less dense and less rigid making the fibrils rearrange themselves along the direction of tensile loading. When fibers were stretched, such arrangements among the fibrils resulted in better load sharing and hence higher stress development in the fiber [23].

During SST, the fibers were shaken for 3 hours in a $4 \%$ basic chromium sulfate $\left(\mathrm{Cr}_{2}\left(\mathrm{SO}_{4}\right)_{3} \bullet 12\left(\mathrm{H}_{2} \mathrm{O}\right)\right)$ solution. The $\mathrm{pH}$ of the solution was maintained about 2-2.5. After 3 hours shaking, a thin coating layer was formed on the fiber surface due to chemical reaction between $\mathrm{Cr}_{2}\left(\mathrm{SO}_{4}\right)_{3} \cdot 12\left(\mathrm{H}_{2} \mathrm{O}\right)$ and fiber (Figure 5).

Again for DST, the same procedure was followed with an additional 2 hours shaking with $\mathrm{NaHCO}_{3}$ in the solution. In this case an even thicker coating was formed on the fiber surface due to chemical reaction between $\mathrm{Cr}_{2}\left(\mathrm{SO}_{4}\right)_{3} \cdot 12\left(\mathrm{H}_{2} \mathrm{O}\right)$ and $\mathrm{NaHCO}_{3}$ and fiber (Figure 6).

The chemical reactions between cellulose of ladies finger fiber and $\mathrm{Cr}_{2}\left(\mathrm{SO}_{4}\right)_{3} \cdot 12\left(\mathrm{H}_{2} \mathrm{O}\right)$ and $\mathrm{NaHCO}_{3}$ occurred in the following three stages.

(i) The chrome complexes reacted with the fiber cellulose carboxyl groups. During the first reaction, the solution was very strong and $\mathrm{pH}$ was around 2 . The chromium held the first $\mathrm{OH}$ group:

$$
\begin{aligned}
& {[\mathrm{Cr}]^{+3}+\mathrm{OH}^{-}} \\
& \quad=[\mathrm{Cr}-\mathrm{OH}]^{++} \quad 33 \% \text { basicity } \mathrm{pH} 2 .
\end{aligned}
$$

(ii) As $\mathrm{pH}$ of the solution was increased, sulfate associated with the chromium became displaced by the hydroxyl 


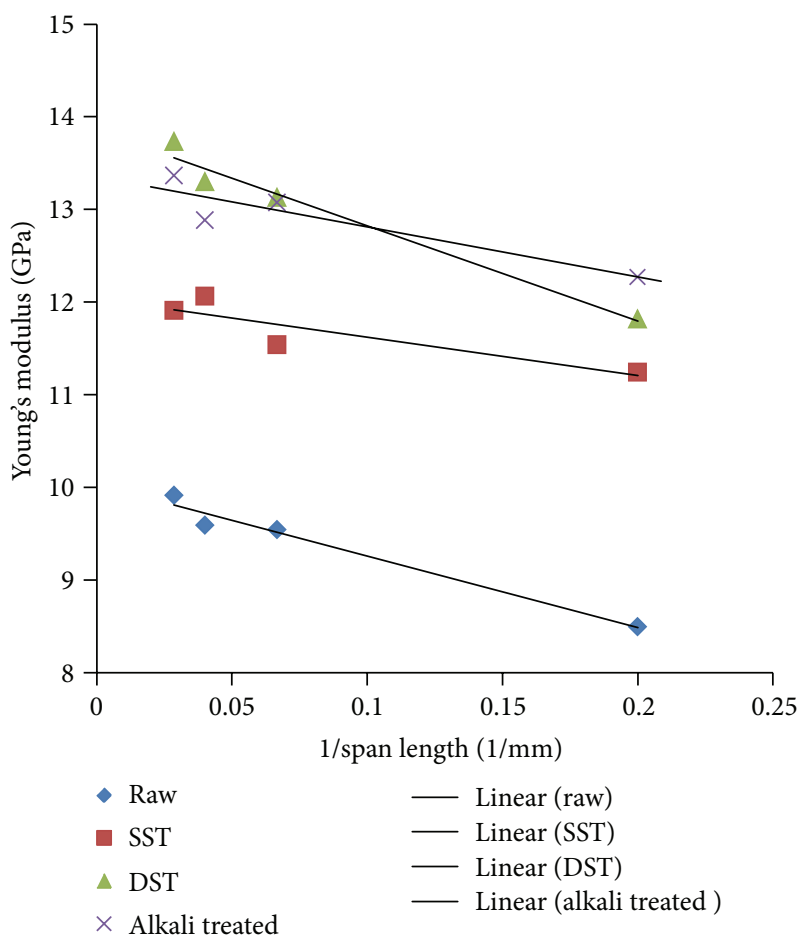

Figure 3: Variation of Young's modulus against 1/span.

groups. Here the second $\mathrm{OH}$ group entered into the reaction with $\mathrm{Cr}$ at $\mathrm{pH}$ 3. During these reactions acidic nature of solution decreased and $\mathrm{pH}$ increased:

$$
\begin{aligned}
& {[\mathrm{Cr}-\mathrm{OH}]^{++}+\mathrm{OH}^{-}} \\
& \quad=\left[\mathrm{Cr}-(\mathrm{OH})_{2}\right]^{+} \quad 66 \% \text { basicity pH 2-pH } 4 .
\end{aligned}
$$

(iii) As $\mathrm{pH}$ was increased to 4, the hydroxyl groups became shared by chromium atoms. When $\mathrm{pH}$ was increased to 8-9, the reaction was completed:

$$
\begin{aligned}
& {\left[\mathrm{Cr}-(\mathrm{OH})_{2}\right]^{+}+\mathrm{OH}^{-}} \\
& \quad=\left[\mathrm{Cr}-(\mathrm{OH})_{2}\right]^{0} \downarrow \quad 100 \% \text { basicity } \mathrm{pH} 4-\mathrm{pH} 8 .
\end{aligned}
$$

After SST, the activity of chromium still remained incomplete. As a result, the tensile properties of ladies fiber increased less compared to the raw ones. However, after the DST, chromium became fully occupied in reducing hydroxyl groups, which in turn increased the tensile properties of ladies finger fiber compared to both raw and SST fibers.

3.2. FTIR Spectroscopic Analysis. FTIR spectra of raw and treated ladies finger fibers are shown in Figure 7. The IR spectrum for raw ladies finger fiber (Figure 7(a)) clearly shows the strong and broad characteristics band of $(-\mathrm{OH})$ at the regions of $3600-3200 \mathrm{~cm}^{-1}$, lignin and hemicelluloses at about $1731.5 \mathrm{~cm}^{-1}$, and $(\mathrm{C}-\mathrm{H})$ aromatic rings and alkane at $2920.5 \mathrm{~cm}^{-1}$ [24]. The alkali treated fiber (Figure 7(b)) shows the characteristics band of $(-\mathrm{OH})$ of high concentration at

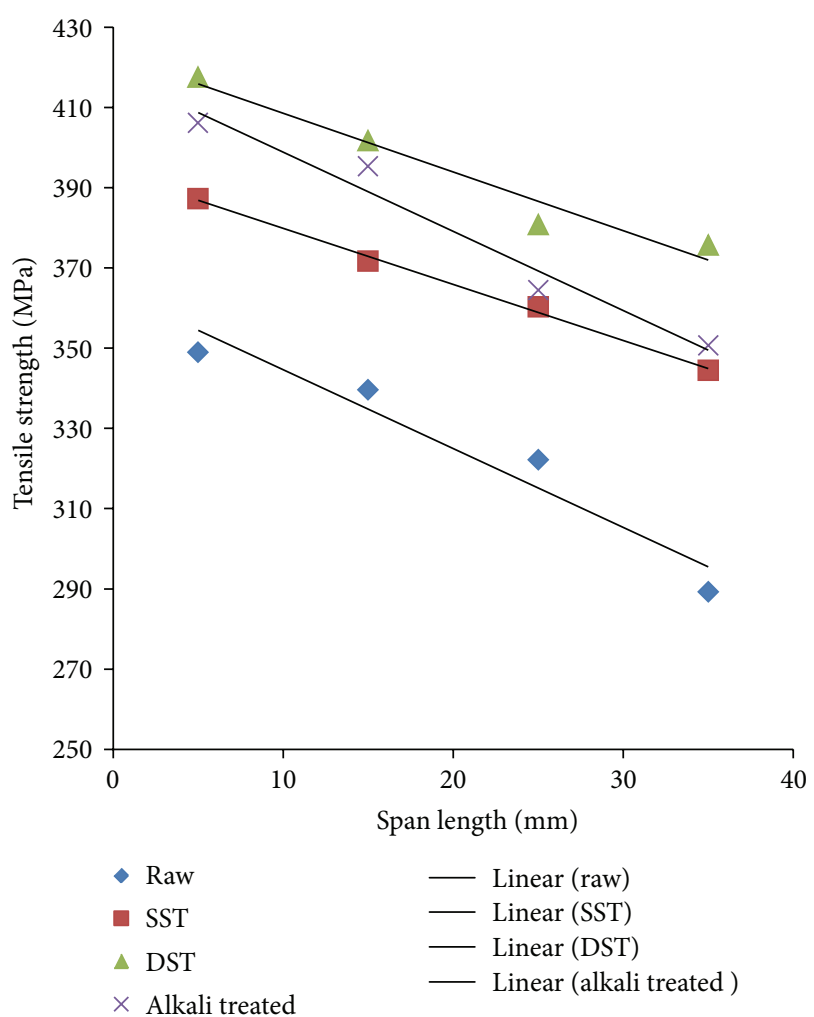

FIGURE 4: Variation of tensile strength against span length.

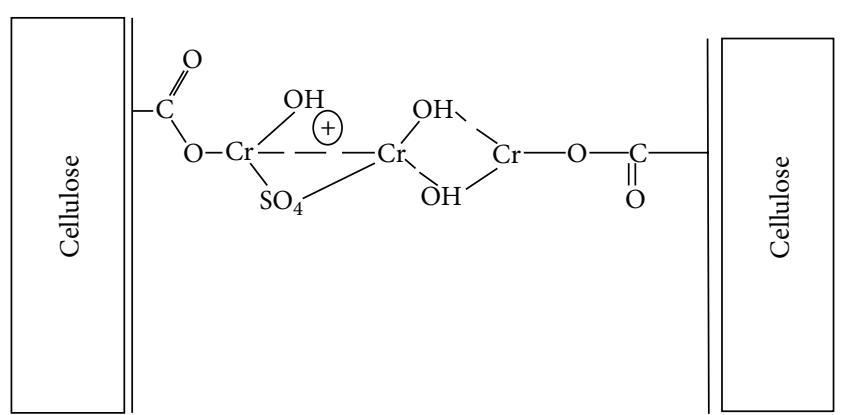

FIGURE 5: Chemical reaction between cellulose of fiber and $\mathrm{Cr}_{2}\left(\mathrm{SO}_{4}\right)_{3} \cdot 12\left(\mathrm{H}_{2} \mathrm{O}\right)$.

around $3452.2 \mathrm{~cm}^{-1}$ and aromatic rings and alkanes at around $2921.8 \mathrm{~cm}^{-1}$. Peaks for lignin and hemicelluloses are not very significant. The basic $\mathrm{Cr}_{2} \mathrm{SO}_{4}$ treatment showed absorption peak at wave number of $3446.7 \mathrm{~cm}^{-1}$ (Figure $7(\mathrm{c})$ ). Double stage basic $\mathrm{Cr}_{2} \mathrm{SO}_{4}$ and $\mathrm{NaHCO}_{3}$ treated fiber showed $(-\mathrm{OH})$ stretching vibration at $3473.6 \mathrm{~cm}^{-1}$ wave number (Figure 7(d)).

3.3. Surface Morphology. Surface morphology of raw, alkali treated, SST, and DST ladies finger fiber was observed under SEM and is shown in Figure 8. The surface of the alkali treated ladies finger fiber was found more rough compared to the raw fiber due to the removal of hemicellulose and lignin from the fiber surface. During single stage treatment and double stage treatment, the surface roughness seemed to be a bit 


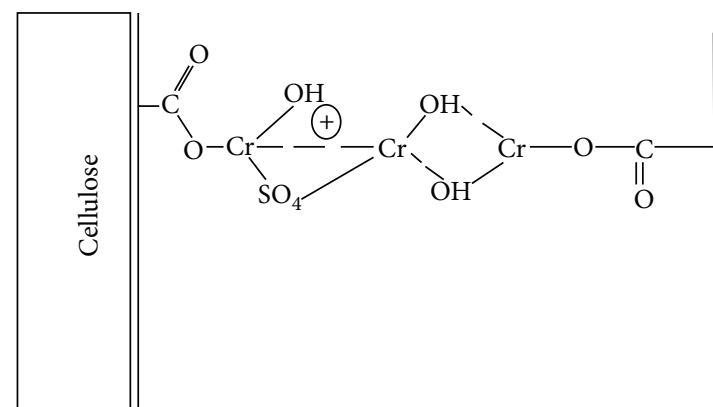

(a)

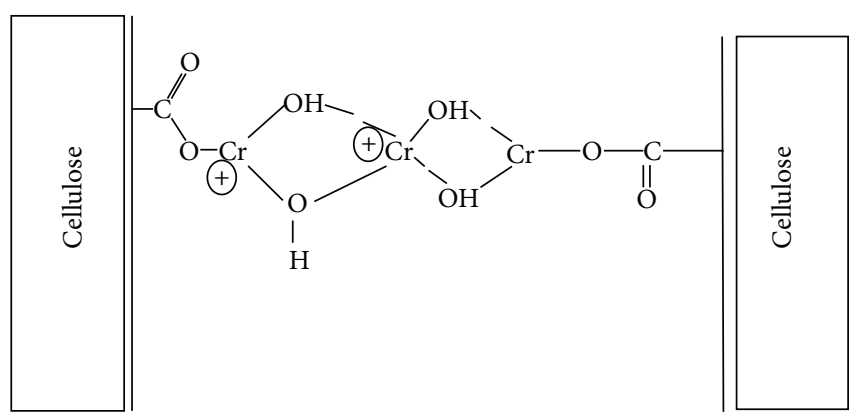

(b)

FIgURE 6: Chemical reaction between cellulose of fiber, $\mathrm{Cr}_{2}\left(\mathrm{SO}_{4}\right)_{3} \bullet 12\left(\mathrm{H}_{2} \mathrm{O}\right)$, and $\mathrm{NaHCO}_{3}$.

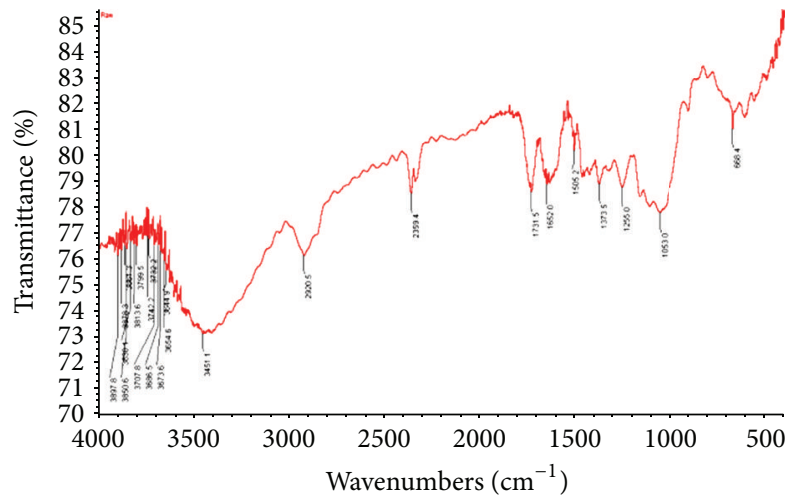

(a)

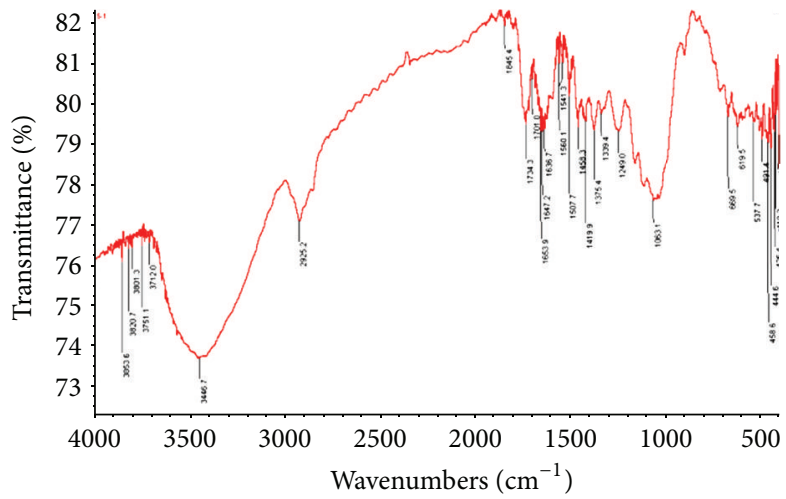

(c)

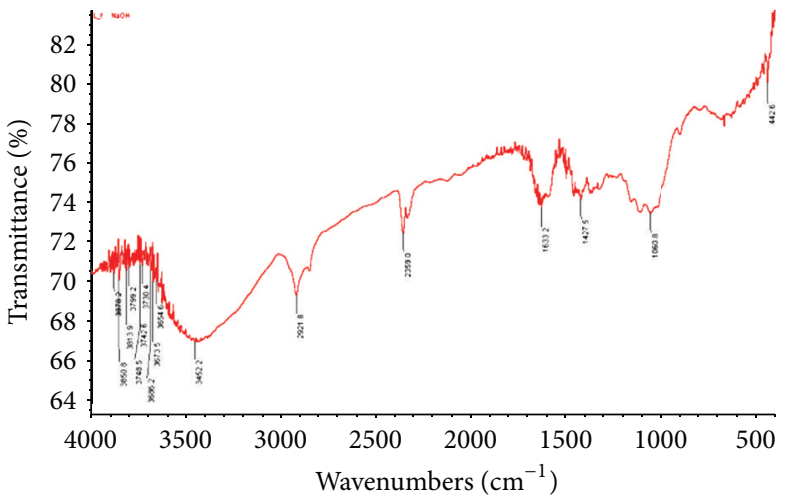

(b)

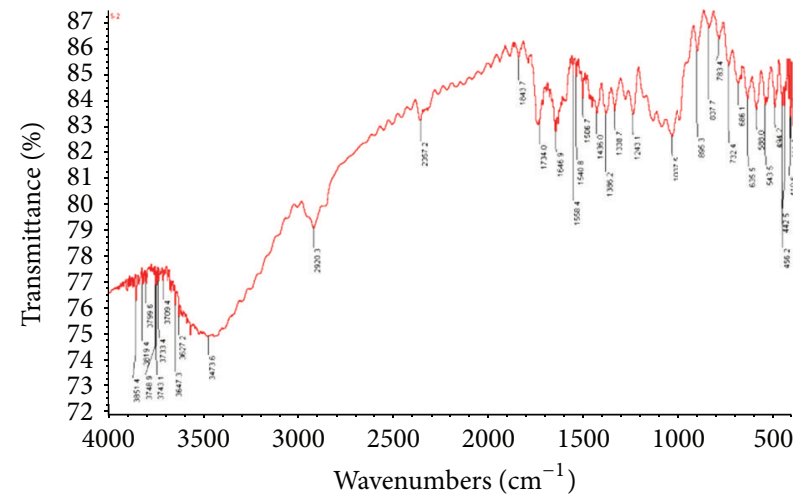

(d)

FIGURE 7: FT-IR spectrum of (a) raw, (b) alkali treated, (c) SST, and (d) DST ladies finger fiber.

reduced. A thin coating layer was formed on the fiber surface during single stage treatment. The thickness of the coating layer was increased during the double stage treatment.

3.4. Thermogravimetric Analysis. Thermo gravimetric analysis was performed on the raw, alkali treated, SST, and DST ladies finger fiber in order to find the effect of chemical treatment on the thermal stability of the fiber. TGA curves of raw and treated ladies finger fibers are shown in Figure 9. There was a huge weight change at around $250^{\circ} \mathrm{C}$ in all four cases indicating the start of thermal decomposition of ladies finger fiber. Thus no significant difference in thermal stability was observed among the raw, alkali treated, SST, and DST fiber of ladies finger.

\section{Conclusion}

Present research demonstrated that chemical treatment clearly affected the mechanical, structural, and thermal properties of fiber obtained from ladies finger plant. The tensile strength of both raw and treated fibers decreased, while Young's modulus increased with span length. The surface of raw ladies finger fiber was rough. Alkali treatment increased the surface roughness by removing hydrophilic hemicellulose. Both single stage and double stage treatments seemed to 


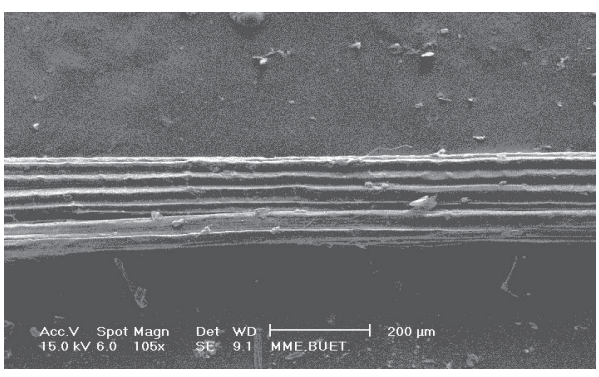

(a)

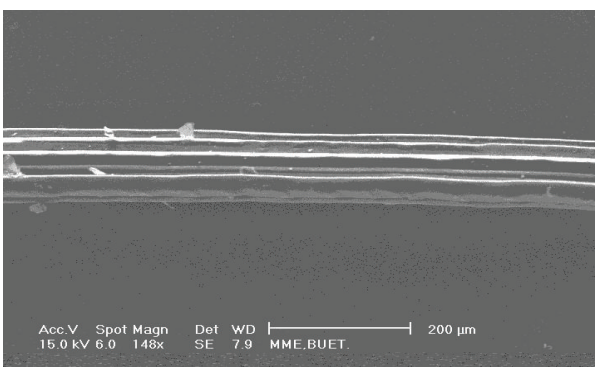

(c)

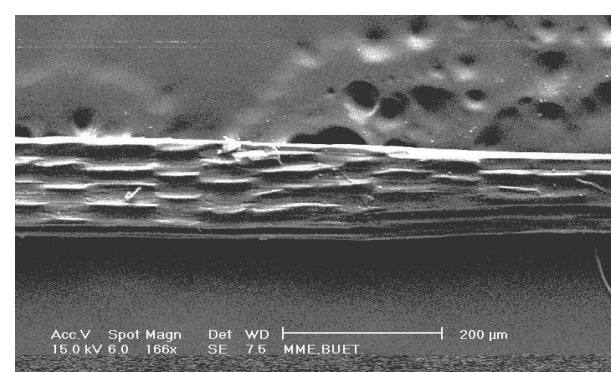

(b)

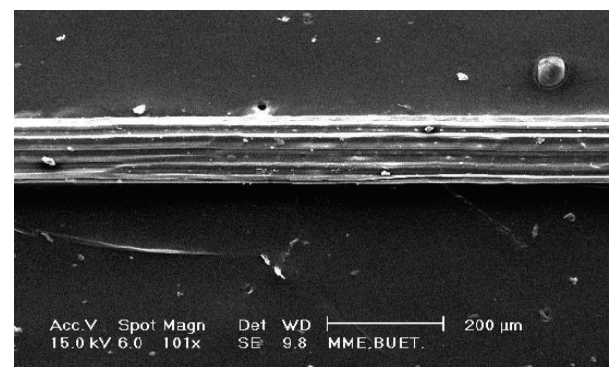

(d)

FIGURE 8: SEM micrographs of (a) raw, (b) alkali treated, (c) SST, and (d) DST ladies finger fiber.

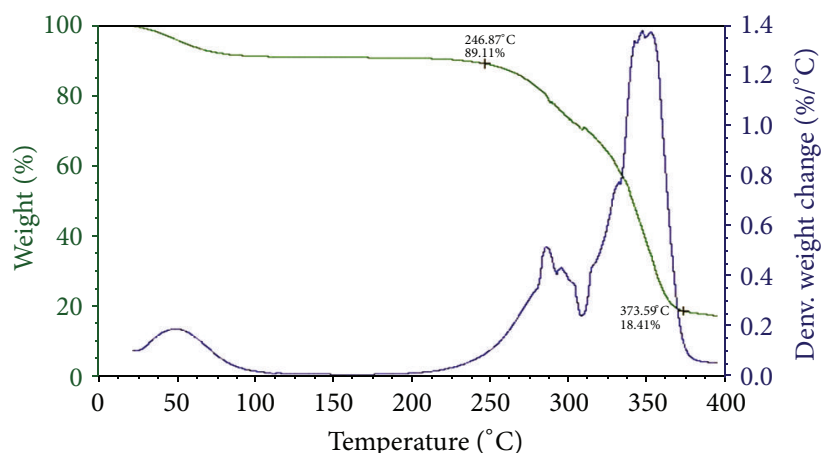

(a)

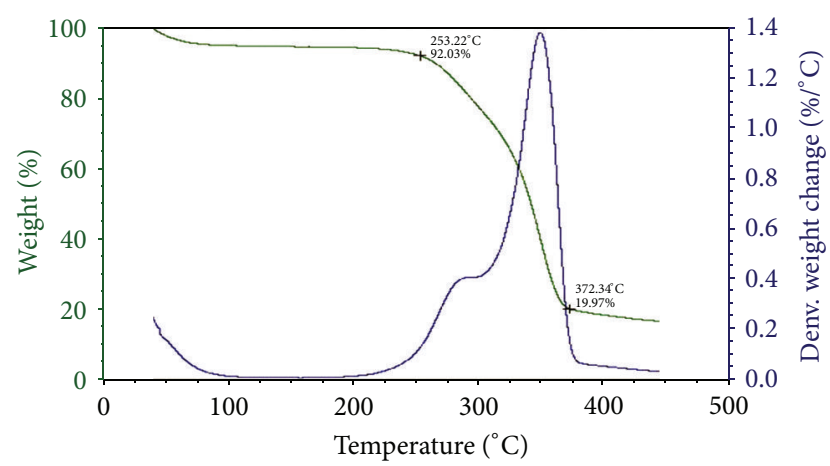

(c)

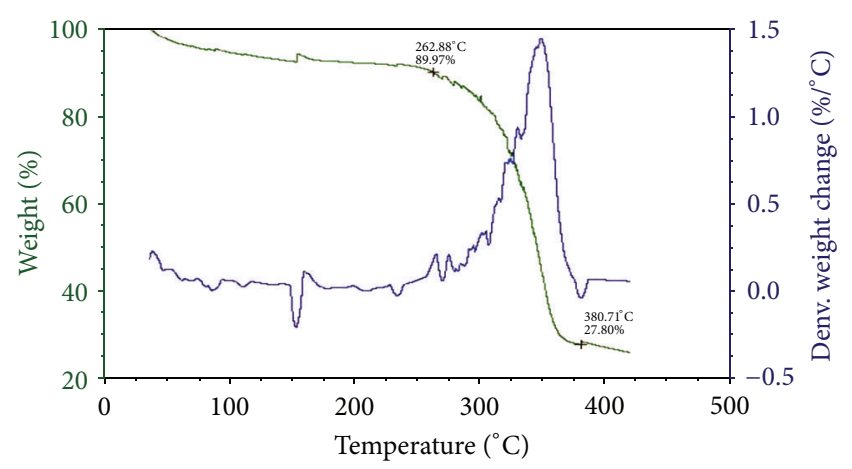

(b)

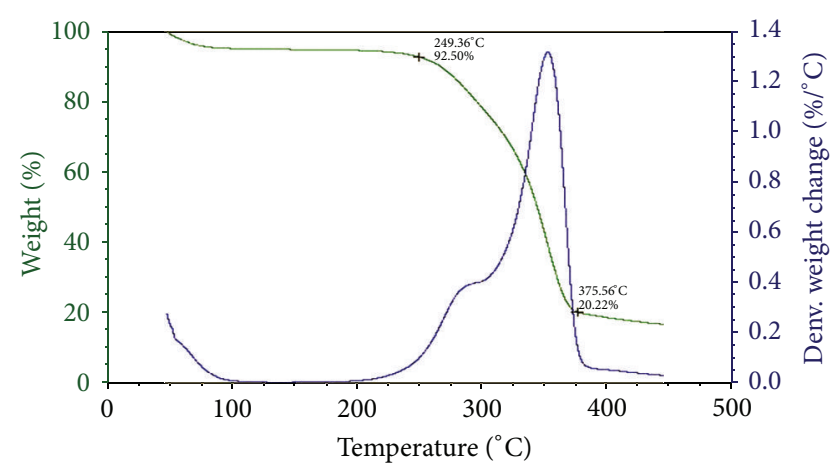

(d)

FIGURE 9: TGA curves of (a) raw, (b) alkali treated, (c) SST, and (d) DST ladies finger fiber.

decrease the surface roughness by forming a coating layer on the fiber surface and improved chemical bonding with cellulose of fiber. As a result all chemical treatment increased the tensile properties of fiber. However, double stage chemical treatment showed better properties compared to alkali treatment and single stage treatment. No significant effect of treatment on thermal stability of fiber was observed from TGA. 


\section{References}

[1] H.-S. Yang, H.-J. Kim, J. Son, H.-J. Park, B.-J. Lee, and T.S. Hwang, "Rice-husk flour filled polypropylene composites; mechanical and morphological study," Composite Structures, vol. 63, no. 3-4, pp. 305-312, 2004.

[2] B. C. Mitra, R. K. Basak, and M. Sarkar, "Studies on jute-reinforced composites, its limitations, and some solutions through chemical modifications of fibers," Journal of Applied Polymer Science, vol. 67, no. 6, pp. 1093-1100, 1998.

[3] A. N. Netravali, Natural Fibers, Plastics and Composites, Kluwer Academic Publisher, 2004.

[4] A. Kelly, "Composite materials," Journal of Ceramic Processing Research, vol. 2, no. 4, pp. 147-154, 2001.

[5] P. Wambua, J. Ivens, and I. Verpoest, "Natural fibres: can they replace glass in fibre reinforced plastics?" Composites Science and Technology, vol. 63, no. 9, pp. 1259-1264, 2003.

[6] A. C. N. Singleton, C. A. Baillie, P. W. R. Beaumont, and T. Peijs, "On the mechanical properties, deformation and fracture of a natural fibre/recycled polymer composite," Composites Part B, vol. 34, no. 6, pp. 519-526, 2003.

[7] M. M. Thwe and K. Liao, "Durability of bamboo-glass fiber reinforced polymer matrix hybrid composites," Composites Science and Technology, vol. 63, no. 3-4, pp. 375-387, 2003.

[8] E. M. F. Aquino, L. P. S. Sarmento, W. Oliveira, and R. V. Silva, "Moisture effect on degradation of jute/glass hybrid composites," Journal of Reinforced Plastics and Composites, vol. 26, no. 2, pp. 219-233, 2007.

[9] M. M. Thwe and K. Liao, "Effects of environmental aging on the mechanical properties of bamboo-glass fiber reinforced polymer matrix hybrid composites," Composites A, vol. 33, no. 1, pp. 43-52, 2002.

[10] S. Joseph, M. S. Sreekala, Z. Oommen, P. Koshy, and S. Thomas, "A comparison of the mechanical properties of phenol formaldehyde composites reinforced with banana fibres and glass fibres," Composites Science and Technology, vol. 62, no. 14, pp. 1857-1868, 2002.

[11] G. Kalaprasad, K. Joseph, and S. Thomas, "Influence of short glass fiber addition on the mechanical properties of sisal reinforced low density polyethylene composites," Journal of Composite Materials, vol. 31, no. 5, pp. 509-527, 1997.

[12] J. Gu, J. Dang, W. Geng, and Q. Zhangh, "Surface modification of HMPBO fibers by silane coupling agent of $\mathrm{KH}-560$ treatment assisted by ultrasonic vibration," Fibers and Polymers, vol. 13, no. 8, pp. 979-984, 2012.

[13] M. R. Ishak, Z. Leman, S. M. Sapuan, M. Z. A. Rahman, and U. M. K. Anwar, "Impregnation modification of sugar palm fibres with phenol formaldehyde and unsaturated polyester," Fibers and Polymers, vol. 14, no. 2, pp. 250-257, 2013.

[14] L. Liu, L. Cheng, L. Huang, and J. Yu, "Enzymatic treatment of mechanochemical modified natural bamboo fibers," Fibers and Polymers, vol. 13, no. 5, pp. 600-605, 2012.

[15] M. M. Haque, M. Hasan, M. S. Islam, and M. E. Ali, "Physicomechanical properties of chemically treated palm and coir fiber reinforced polypropylene composites," Bioresource Technology, vol. 100, no. 20, pp. 4903-4906, 2009.

[16] M. R. Rahman, M. M. Huque, M. N. Islam, and M. Hasan, "Mechanical properties of polypropylene composites reinforced with chemically treated abaca," Composites A, vol. 40, no. 4, pp. 511-517, 2009.
[17] M. R. Rahman, M. Hasan, M. M. Huque, and M. N. Islam, "Physico-mechanical properties of jute fiber reinforced polypropylene composites," Journal of Reinforced Plastics and Composites, vol. 29, no. 3, pp. 445-455, 2010.

[18] M. Haque, R. Rahman, N. Islam, M. Huque, and M. Hasan, "Mechanical properties of polypropylene composites reinforced with chemically treated coir and abaca fiber," Journal of Reinforced Plastics and Composites, vol. 29, no. 15, pp. 2253-2261, 2010.

[19] S. Biswas, Characterization and Performance Analysis of Natural Fibers as Reinforcement in Polymer Composite [M.Phil thesis], Bangladesh University of Engineering and Technology, Bangladesh, 2010.

[20] S. Biswas, Q. Ahsan, I. Verpoest, and M. Hasan, "Effect of span length on the tensile properties of natural fibers," Advanced Materials Research, vol. 264-265, pp. 445-450, 2011.

[21] S. S. Mir, S. M. N. Hasan, M. J. Hossain, and M. Hasan, "Chemical modification effect on the mechanical properties of coir fiber," Engineering Journal, vol. 16, no. 2, pp. 73-83, 2012.

[22] A. K. Bledzki and J. Gassan, "Composites reinforced with cellulose based fibres," Progress in Polymer Science, vol. 24, no. 2, pp. 221-274, 1999.

[23] P. V. Joseph, K. Joseph, S. Thomas et al., "The thermal and crystallisation studies of short sisal fibre reinforced polypropylene composites," Composites A, vol. 34, no. 3, pp. 253-266, 2003.

[24] N. Nafsin, Manufacturing and Characterization of Coir Fiber Reinforced Polypropylene Composite [B.Sc. thesis], University of Engineering and Technology, Bangladesh, 2011. 

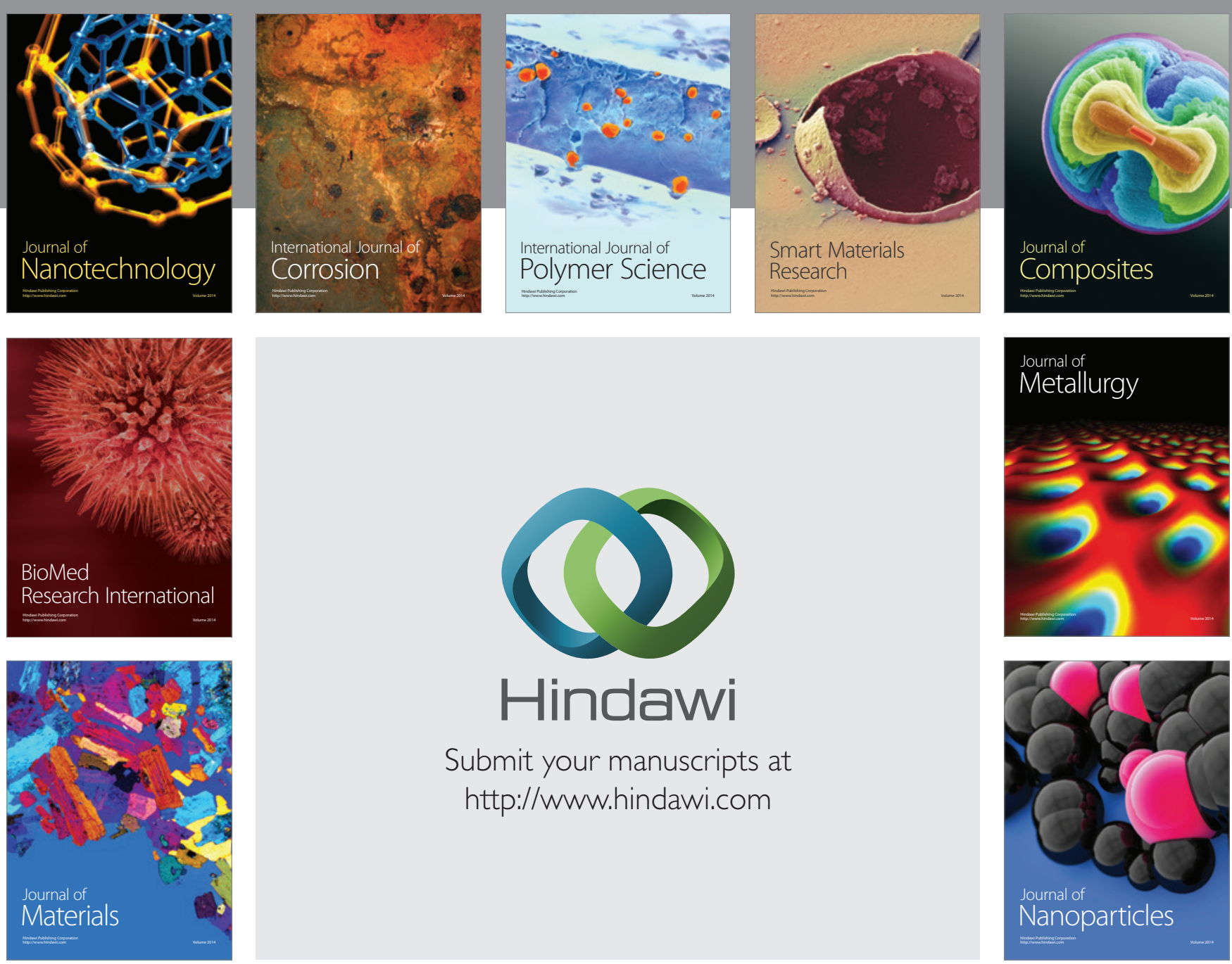

Submit your manuscripts at http://www.hindawi.com
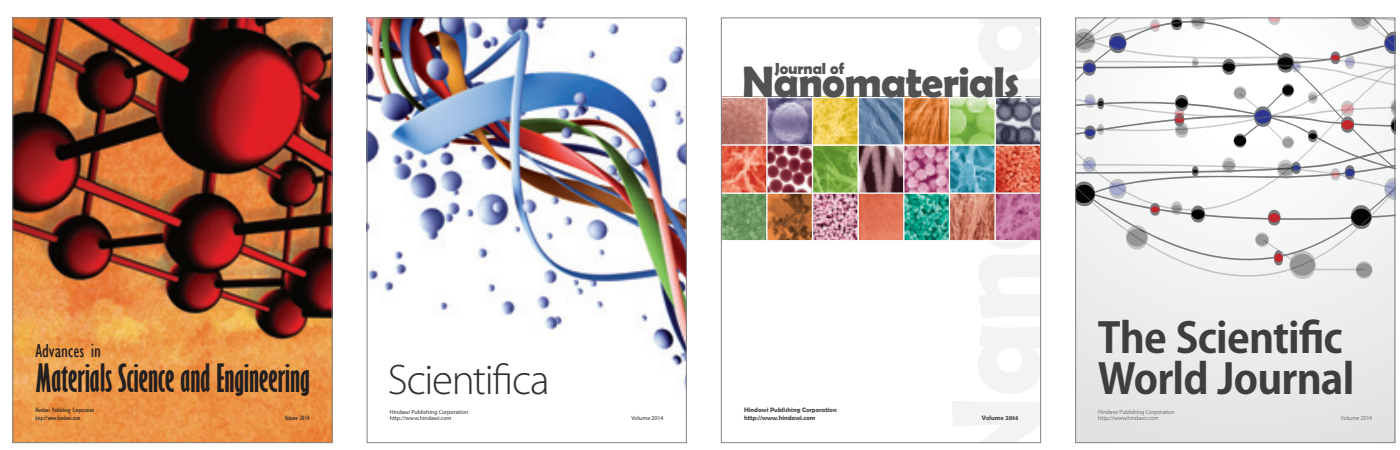

\section{The Scientific World Journal}
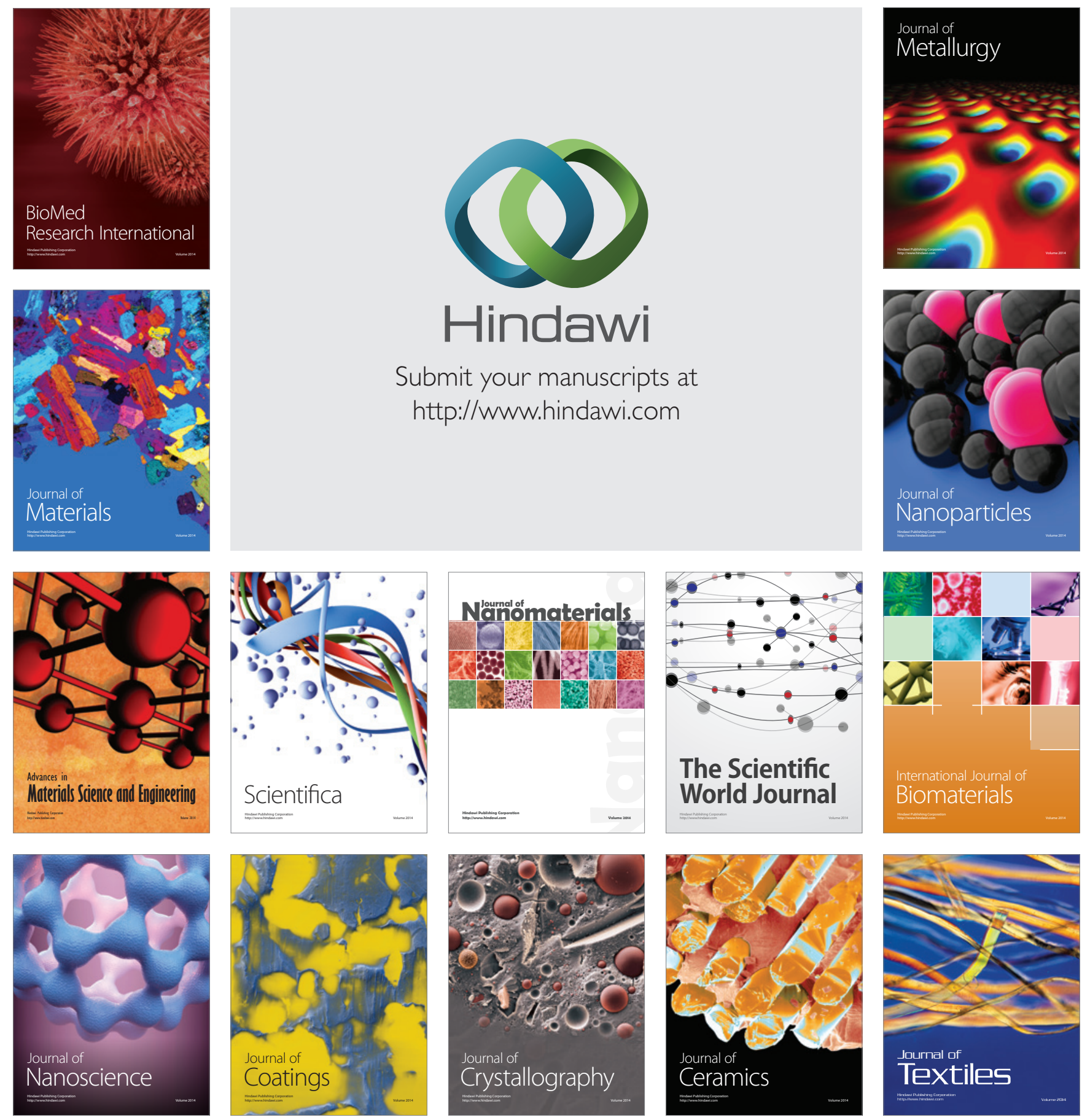